\title{
Characterization of Ottawa Sand and Application to Blast Simulations
}

\author{
Sidney Chocron ${ }^{1 *}$, Alexander Carpenter ${ }^{1}$, Arthur Nicholls ${ }^{1}$, James Walker ${ }^{1}$, Ohad Elbaz ${ }^{2}$, \\ Elisha Rejovitzky ${ }^{2}$ \\ ${ }^{1}$ Southwest Research Institute, 6220 Culebra Rd, San Antonio, TX 78238, USA \\ ${ }^{2}$ Rafael LTD, Haifa 3102102, Israel
}

\begin{abstract}
The present work aims at presenting consistent data both from laboratory characterization and from blast tests to see how a computer model performs when only data from mechanical tests are being fed to the constitutive model. A sand (Ottawa 20-30) that meets ASTM C778 requirements, i.e., well characterized microscopically, was tested in triaxial compression under confinement pressures ranging from 50 to $300 \mathrm{MPa}$ and moisture contents of 0 to $15 \%$ as well as high strain-rates. These tests provided both the experimental equation of state (pressure vs. volume) and compaction curves as well as the strength vs. pressure properties to build a constitutive model both in LS-DYNA and CTH. Blast tests were subsequently performed by burying explosive at three different depths inside a sand pot with a rigid steel plate on top. During flight, the height of the steel plate was tracked with Phantom high-speed cameras to determine the impulse transmitted to the plate as well as the maximum jump height. Simulations were performed with both an Eulerian code (CTH) and a Lagrangian/ALE code (LS-DYNA) using the constitutive model determined during the material characterization. The predictions of both codes are as close as $7 \%$ and as far as $22 \%$, depending on the test configuration.
\end{abstract}

\section{Introduction}

Finding well-characterized and well-controlled blast tests in the literature is extremely difficult (1-3). Many times expensive blast tests lack essential information like moisture content of the soil, density, and other important parameters. Consistent data with laboratory soil characterization (ambient and high pressures and low and high strain-rates) performed concurrently with blast tests is even more difficult to find. The present work by the team Southwest Research Institute (SwRI)/Rafael aims at presenting mechanical characterization data, in particular triaxial compression tests, and data from blast performed on a standard material to validate computer models of blast events.

The sections below summarize the material characterization work, blast tests, and computer simulations performed on a standard sand called Ottawa 20-30, that meets ASTM C778.

\footnotetext{
*Corresponding author email : sidney.chocron@swri.org
} 


\section{Materials and summary of characterization tests}

\subsection{Materials}

The first sand is a silica sand with brand name ASTM Ottawa 20-30 sand which meets the ASTM C778 requirements. It is manufactured to pass No. $20(850 \mu \mathrm{m})$ sieve and be retained on No. $30(600 \mu \mathrm{m})$. This specially graded sand for ASTM tests is made of naturally rounded silica sands of nearly pure quartz, mined from the Ottawa, Illinois area. The sand was purchased from https://www.certifiedmtp.com in bags of $50 \mathrm{lbs}$. The matrix density was measured for Ottawa sand giving $2.685 \mathrm{~g} / \mathrm{cm}^{3}$.
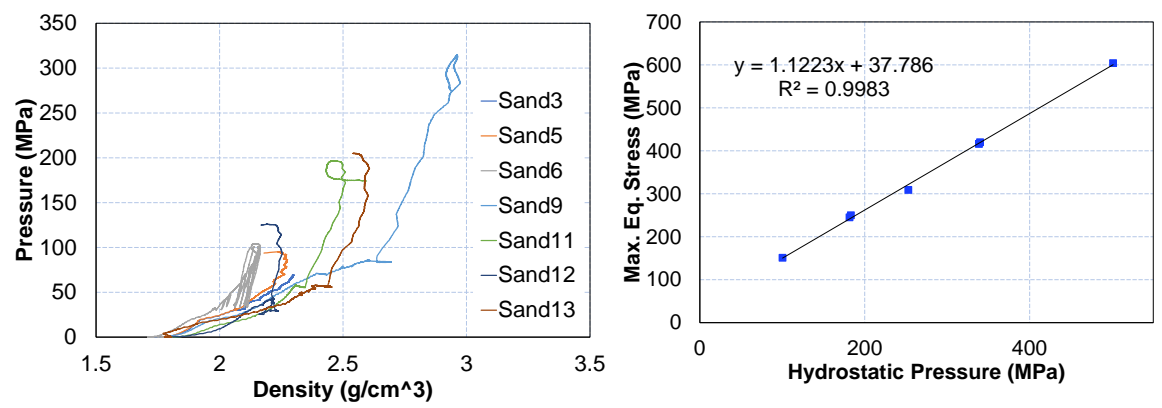

Figure 1. Ottawa Sand a) Compaction curves, b) Strength vs. Pressure.

ASTM sand is expensive so the project's limited funding did not allow performing all the tests with this sand. Five out of the eight blast tests performed used "washed play sand" with brandname Quikrete n. 1113 that comes in 50-pound bags, purchased from a local vendor. The density of the sand was not measured on-site but when the sand was poured in similar conditions at SwRI, the density achieved was $1.50 \mathrm{~g} / \mathrm{cm}^{3}$.

\subsection{Quasistatic Tests}

The Ottawa sand was tested in triaxial compression to find the compaction curves (pressure vs. density) as well as the strength vs. hydrostatic pressure as a function of moisture content. The results are summarized in Figure 1. Although mechanical tests were also performed on wet sand, they are not summarized here because all blast tests were performed with dry sand. The curves were implemented both in CTH and LS-DYNA models to compute blast events.

\subsection{High Strain-Rate Tests}

The 10-mm length of the sand specimen was determined using LS-DYNA simulations to ensure specimen equilibrium. Specimens were confined using a copper sleeve. Different confinement pressures were achieved by varying the thickness of the sleeve.

The sand model (Equation of state and strength model) from the static tests shown above was used for the numerical simulations of the dynamic tests and the results were compared to the test data for the $0.4 \mathrm{~mm}$ copper sleeve. The comparison of the transmitted signals is presented in Figure 2a. The simulation shows a lower velocity transmitted signal in comparison with the test. This may indicate rate dependency of the sand. A comparison of the simulated Von-Misses stress in the sample compared to the calculated stress and strain rate from the tests is presented in Figure $2 b$. 

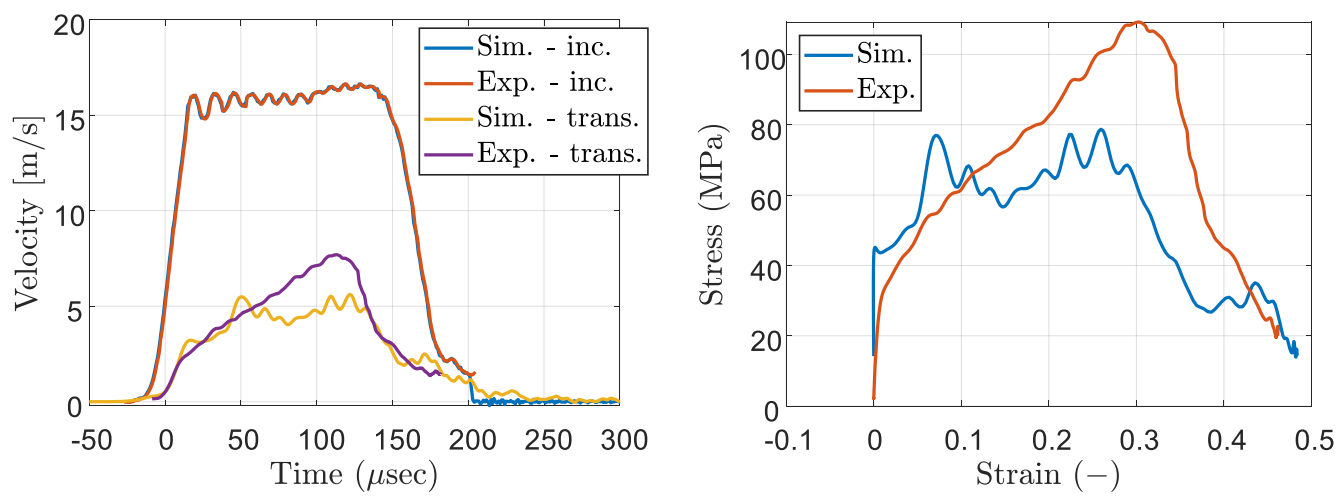

Figure 2. Test comparison with simulations using quasistatic model a) Velocity vs. time, b) von Mises stress vs. strain

The comparison shows lower stresses developing in the sand sample using the static model. Figure 3 shows the test results and simulation for a very thick sleeve $(5 \mathrm{~mm})$, i.e. rigid confinement.

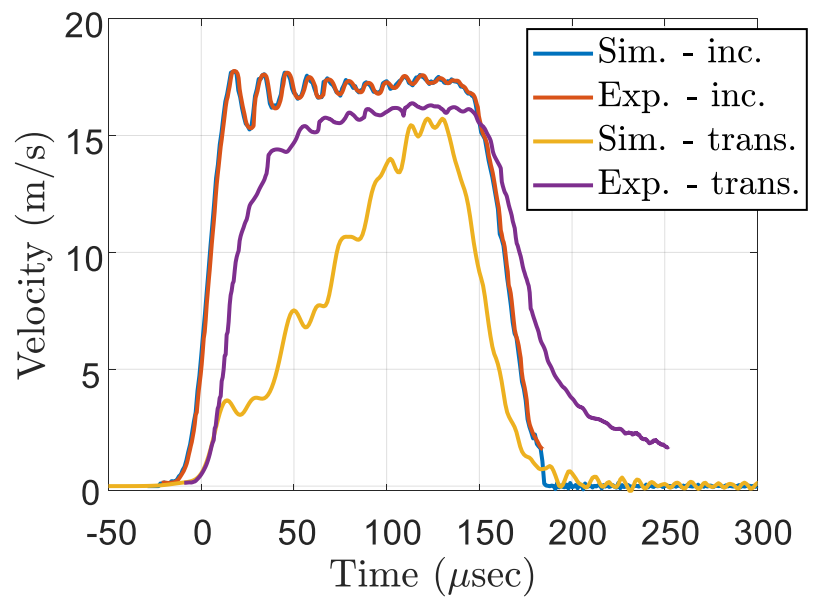

Figure 3. Test comparison with numerical calcs. using quasitatic model for rigid sleeve.

The simulation results using the quasistatic material model show again a lower velocity transmitted signal than the test, indicating a possible rate dependency in the sand.

\section{Summary of blast experiments and results}

The tests consisted of the explosive loading of a steel plate placed onto the top of a sand pot (Figure 4a), with a 100 gram C-4 explosive charge buried at different depths in the sand. The steel plate behaved as rigid and had nominal dimensions of $45.7 \mathrm{~cm} \times 45.7 \mathrm{~cm} \times 1.27 \mathrm{~cm}$ (mass of $20.5 \mathrm{~kg}$ ). The main diagnostics were a high-speed video camera and a string potentiometer attached to the plate. Accelerometers were also attached but data from the camera and string pot were to provide reliable position vs. time data. 
Figure $4 \mathrm{~b}$ shows an example of the information provided by the diagnostics as well as by free-fall theory. The data obtained with the video camera are represented as the open squares, and the red continuous line is from the string potentiometer. They both match, although the string potentiometer "jumps" at the beginning of the blast due to the inertia of the device.

The initial velocity imparted to the plate by the explosive was measured using the first frames from the event. The initial velocity was then used to predict the trajectory of the plate using free fall theory. Figure $4 \mathrm{~b}$ shows that the predicted history matches well the camera and string pot data, i.e. provides additional validation of the data captured.
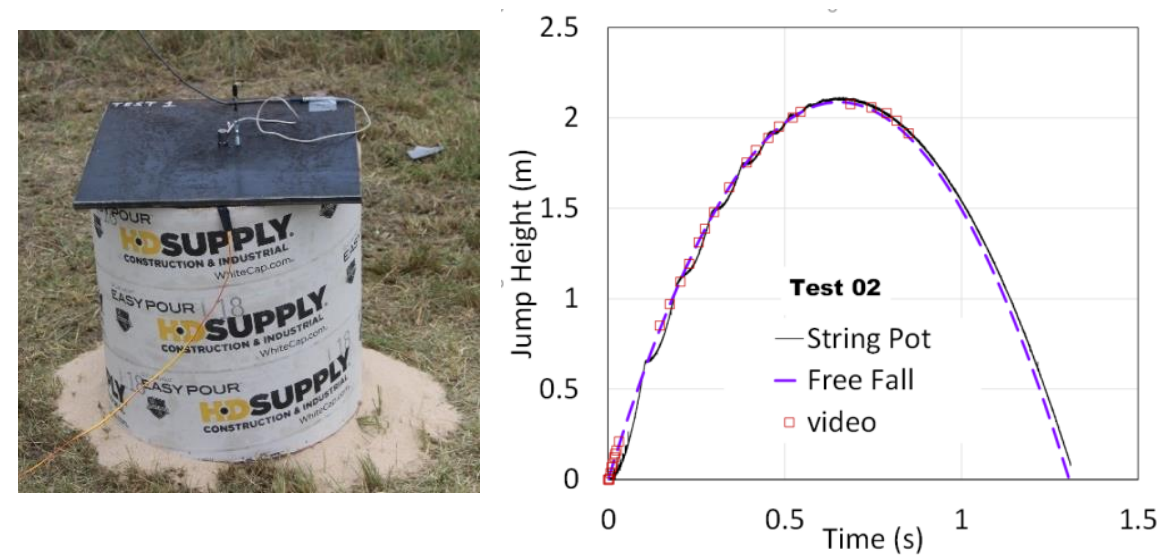

Figure 4. a) Sand Pot with Steel Plate on Top. b) Data recorded during a test.

Table 1 provides a summary of the test results for the jump height and initial plate velocities. The depth of burial (DOB) is measured to the center of the charge. The string pot jump is directly read from the string pot data. High-speed video (HSV) velocity is determined by fitting the initial slope of the HSV data to a free-fall theoretical equation. The "Theory Jump" columns uses the same equation and provides the maximum jump obtained with it. The three methods of estimating jump height provide similar answers. Only one test was performed with a DOB of 11.75 inches $(29.8 \mathrm{~cm})$ because the high-speed video clearly showed the lateral expansion of the sand was happening much earlier than impulse on the plate.

Some of the tests were performed to be nominally identical to check for data scatter, which is a common issue when performing blast tests. Tests 3 and 4, with play sand, were both at DOB of 6.75 inches $(17.1 \mathrm{~cm})$ and identical. The jump height is $4.41 \mathrm{~m}$ for test 3 and $4.5 \mathrm{~m}$ for test 4 , i.e. the scatter is very small for this particular test $(\sim 2 \%)$. For the tests performed with the ASTM sand (number 5 and 7) at a DOB of 8.75 inches $(22.2 \mathrm{~cm})$, the jump height was, respectively, $2.83 \mathrm{~m}$ and $2.72 \mathrm{~m}$, i.e. a scatter of $\sim 4 \%$. The largest scatter was seen when comparing tests 2 and 6, nominally identical sand and DOB of 8.75 in with a respective jump heigh of $2.09 \mathrm{~m}$ and $2.50 \mathrm{~m}$. The scatter is $\sim 16 \%$, which is still acceptable and expected for this kind of tests.

Finally, a comparison between the play sand and the ASTM sand is performed, even though only three tests were performed with the ASTM sand because of cost constraints. The average plate jump height for ASTM sand is systematically larger than for the play sand. Given than the ASTM sand is 4\% denser than the play sand, it is expected to provide more momentum to the plate. It is interesting that the ratio stays somewhat consistent for the two DOBs tested. For a DOB of 6.75 inches, the jump with the ASTM sand is on average $24 \%$ larger than the play sand. For a DOB of 8.75 inches, it is $21 \%$ larger. 
Table 1. Test Results Summary

\begin{tabular}{|c|c|c|c|c|c|c|}
\hline $\begin{array}{c}\text { Test } \\
\text { No. }\end{array}$ & $\begin{array}{c}\text { Sand } \\
\text { Type }\end{array}$ & $\begin{array}{c}\text { DOB } \\
(\mathrm{in} / / \mathrm{cm})\end{array}$ & $\begin{array}{c}\text { String Pot } \\
\text { Jump }(\mathrm{m})\end{array}$ & $\begin{array}{c}\text { HSV Velocity } \\
(\mathrm{m} / \mathrm{s})\end{array}$ & $\begin{array}{c}\text { HSV Jump } \\
(\mathrm{m})\end{array}$ & $\begin{array}{c}\text { Theory } \\
\text { Jump }(\mathrm{m})\end{array}$ \\
\hline 1 & Play & $11.75 / / 29.8$ & 1.27 & 5 & 1.16 & 1.27 \\
\hline 2 & Play & $8.75 / / 22.2$ & 2.12 & 6.4 & 2.08 & 2.09 \\
\hline 3 & Play & $6.75 / / 17.1$ & NA & 9.3 & NA & 4.41 \\
\hline 4 & Play & $6.75 / / 17.1$ & NA & 9.4 & NA & 4.50 \\
\hline 5 & ASTM & $8.75 / / 22.2$ & 2.93 & 7.5 & 2.82 & 2.83 \\
\hline 6 & Play & $8.75 / / 22.2$ & 2.52 & 7 & 2.51 & 2.50 \\
\hline 7 & ASTM & $8.75 / / 22.2$ & 2.71 & 7.3 & 2.71 & 2.72 \\
\hline 8 & ASTM & $6.75 / / 17.1$ & NA & 10.4 & NA & 5.51 \\
\hline
\end{tabular}

\section{Computational methods}

\subsection{CTH COMPUTATIONS}

\subsubsection{Geometry and Mesh}

The geometry of the blast tests was assumed to be 2D axisymmetric in the CTH simulations. A $100 \mathrm{~g} \mathrm{C} 4$ charge with a 4-cm diameter and 4.94-cm height was placed within a soil pot with a diameter of $45.6 \mathrm{~cm}$ and length of $67.8 \mathrm{~cm}$. An additional $55 \mathrm{~cm}$ of soil was placed below the soil pot in the computations. Test data was obtained using the ASTM Ottawa sand at two different depth of burials, 17.1 and $22.2 \mathrm{~cm}$, so computations were performed for each of these conditions. An example image of the initial material configuration is shown in Figure 5. A mesh size of $5 \mathrm{~mm}$ was used in both the radial and axial directions.
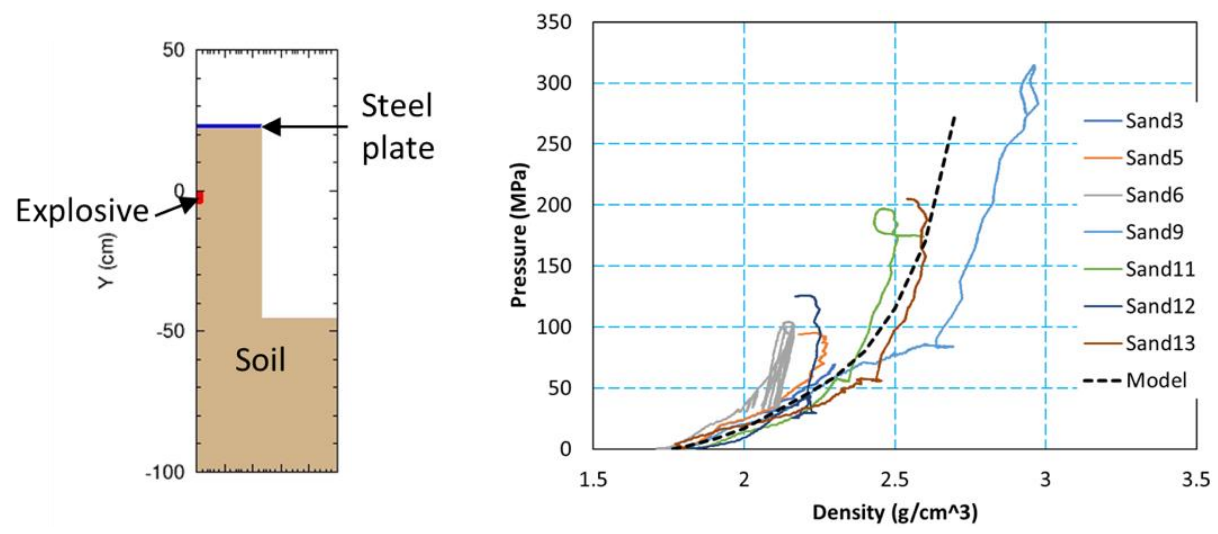

Figure 5. a) CTH Material Setup (Initial Configuration) b) Pressure-Density relationship implemented in $\mathrm{CTH}$ for Ottawa Sand

\subsubsection{Material Models}

Equivalent stresses measured from the soil compression tests can be plotted against the corresponding pressures to obtain a pressure-dependent strength relationship. The maximum equivalent stress from each Ottawa sand test is plotted against pressure in Figure 1b. A linear relationship can be fit to the data. The slope and y-intercept of the best fit line can be input as material constants for Drucker-Prager model in CTH. There is no evidence of the 
equivalent stress-pressure relationship leveling off at the pressures tested, so the asymptotic strength value was assumed to be very large (e.g. 1e30). In the absence of measurements, the Poisson's ratio was set to 0.364 , while the melting temperature was set to $1740 \mathrm{~K}$.

The equations of state for the soil materials can be defined using a pressure vs. density relationship. CTH contains a FOAM equation of state that allows the relationship to be defined in a piecewise manner using a table with pressure-density points. The relationships used in the simulations are compared to the data from the various tests is in Figure 5b. The initial and fully compressed densities of the Ottawa sand were defined as 1.764 and $2.6 \mathrm{~g} / \mathrm{cm}^{3}$, respectively. Load/unload tests were performed in CTH to insure proper implementation of the material model. For this first set of blast simulations the strain-rate effects observed in the materials section were ignored, but probably should be implemented in refined computations.

The steel plate in the blast computations was simulated using the Johnson-Cook strength model and a conventional equation of state. The detonation of the $\mathrm{C} 4$ explosive was simulated using the Jones-Wilkins-Lee equation of state.

\subsection{LS-DYNA COMPUTATIONS}

\subsubsection{Geometry and Meshes}

The blast simulations were also performed in LS-DYNA. An arbitrary Lagrangian-Eulerian (ALE) approach was used in these computations. The soil, explosive, and surrounding air were all modeled using ALE multi-material elements, while the steel plate was modeled using solid constant stress elements. The dimensions of the soil pot, explosive, and steel plate were identical to those from the CTH simulations, but a 3D geometry with two planes of symmetry were used instead of the 2D axisymmetric geometry from the $\mathrm{CTH}$ simulations.

\subsubsection{Material Models}

The LS-DYNA implementations of the soil models utilized the *MAT_PSEUDO_TENSOR material model and the *EOS_TABULATED_COMPACTION equation of state. These models allow for a material's equivalent stress-pressure and pressure-volumetric strain relationships to be defined, respectively, in a tabulated manner. Because volumetric strain is directly related to a material's density, the soil behavior can be defined in LS-DYNA in a manner similar to that performed in $\mathrm{CTH}$. The keywords used in the actual runs are included in the Appendix.

Single element LS-DYNA simulations were used to confirm that the soil models behave appropriately under both loading and unloading conditions. The single elements were compressed and unloaded hydrostatically. As in CTH, the results indicate that the LS-DYNA soil model was behaving as intended. Again, no strain-rate effects were incorporated in these computations.

\section{SIMULATION RESULTS AND COMPARISON TO EXPERIMENTS}

\subsection{CTH Computations}

An example of how the material deforms in one of the CTH simulations is presented in Figure 6a. The blast launches the steel plate, shown in blue, vertically upwards. The momentum of the plate in this direction can be queried as a function of time. The momentum eventually 


\section{DYMAT 2021}

reaches a steady-state value which is equal to the impulse imparted by the explosive and soil. The values from the compuations are compared to the test measurements in Table 2. Although the impulse values from the CTH simulations do not match the test data exactly, they are close enough that the soil model is likely providing a reasonable approximation of the material's actual response.
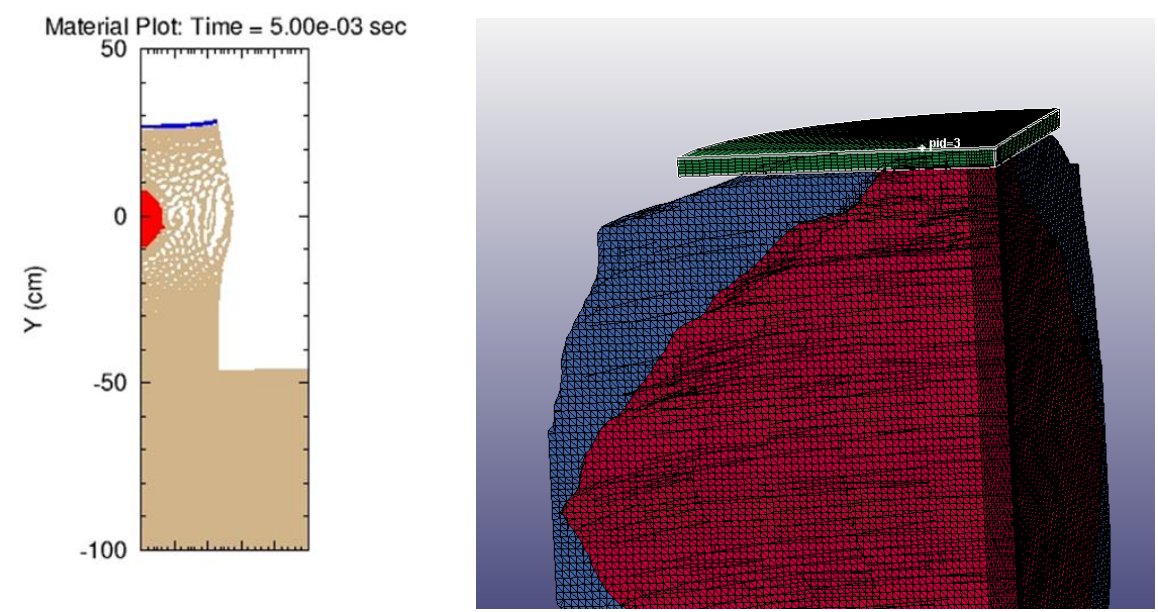

Figure 6. a) Example CTH Results (22.2 cm depth of burial), b) Example LS-DYNA Results (17.1 cm depth of burial).

Table 2. CTH Results Summary

\begin{tabular}{|c|c|c|c|}
\hline $\begin{array}{c}\text { DOB } \\
(\mathrm{cm})\end{array}$ & $\begin{array}{c}\text { Test Impulse } \\
(\mathrm{kg}-\mathrm{m} / \mathrm{s})\end{array}$ & $\begin{array}{c}\text { Sim Impulse } \\
(\mathrm{kg}-\mathrm{m} / \mathrm{s})\end{array}$ & $\begin{array}{c}\text { Percent Diff. } \\
(\%)\end{array}$ \\
\hline 17.1 & 212 & 195 & -8.0 \\
\hline 22.2 & 154 & 192 & 24.7 \\
\hline
\end{tabular}

\subsection{LS-DYNA}

An example of how the ALE mesh deforms in the LS-DYNA blast simulations is presented in Figure 6b. As with the CTH simulations, the vertical velocity of the plate reached a steadystate value that was multiplied by the mass of the steel plate $(\times 4$ to account for the two planes of symmetry) to determine the impulse imparted by the explosive and soil. Table 3 shows how the LS-DYNA results compared to the test measurement. The LS-DYNA simulations resulted in slightly more impulse than measured from the tests, but the results from the simulations are still somewhat reasonable.

Table 3. LS-DYNA Results Summary

\begin{tabular}{|c|c|c|c|}
\hline $\begin{array}{c}\text { DOB } \\
(\mathrm{cm})\end{array}$ & $\begin{array}{c}\text { Test Impulse } \\
(\mathrm{kg}-\mathrm{m} / \mathrm{s})\end{array}$ & $\begin{array}{c}\text { Sim Impulse } \\
(\mathrm{kg}-\mathrm{m} / \mathrm{s})\end{array}$ & $\begin{array}{c}\text { Percent Diff. } \\
(\%)\end{array}$ \\
\hline 17.1 & 212 & 252 & 18.9 \\
\hline 22.2 & 154 & 169 & 9.7 \\
\hline
\end{tabular}




\section{CONCLUSIONS}

SwRI performed triaxial compression of the ASTM Ottawa and Yehu clay soils to obtain pressure vs. density and strength vs. pressure curves. These curves were implemented as material models in both CTH and LS-DYNA. Blast tests on a rigid steel plate were performed using the ASTM sand and also local sand for two different explosive depths of burial. Impulse predicted by the codes matched the experimental results within a 8 to $25 \%$ error.

\section{References}

1. Walker JD, Grosch DJ, Moore TZ, Grimm M, Chocron S. Statistical variations in blast loads from buried explosives. In: Proceedings - 30th International Symposium on Ballistics, BALLISTICS 2017. 2017.

2. Anderson CE, Behner T, Weiss CE. Mine blast loading experiments. Int J Impact Eng [Internet]. 2011 Aug [cited 2014 Dec 10];38(8-9):697-706. Available from: http://linkinghub.elsevier.com/retrieve/pii/S0734743X11000662

3. Anderson Jr. C, Behner T, Weiss CE, Chocron S, Bigger RP. Mine Blast Loading: Experiments and Simulations. 2010. 